\title{
PERCEPÇÕES DE MULHERES PROFISSIONAIS EM MEIO AO CENÁRIO DA REESTRUTURAÇÃO PRODUTIVA: A PERSISTÊNCIA DE UMA EMANCIPAÇÃO LIMITADA?
}

\author{
Patrícia Maria Figueiredo' \\ Liane Carly Hermes Zanella²
}

\section{Resumo}

Esta pesquisa objetivou avaliar como as representações sociais de gênero influenciam na vida profissional das mulheres no atual contexto marcado pela reestruturação produtiva. Com esse intuito, foi realizado um estudo descritivo aplicado em uma organização pertencente ao setor de equipamentos para telecomunicações. A aplicação de entrevistas semi-estruturadas correspondeu à técnica de coleta de dados empreendida. Os resultados obtidos pela pesquisa indicam que as entrevistadas são submetidas à dupla jornada de trabalho. A divisão de atividades profissionais de acordo com o sexo do trabalhador está presente na organização estudada e é conseqüência em parte de aspectos inerentes à sua cultura organizacional. Constata-se a ocorrência do fenômeno do "teto de vidro", ou seja, um obstáculo sutil que inibe a ascensão profissional de mulheres na empresa analisada. $\mathrm{O}$ advento da reestruturação produtiva, em relação à autonomia e ao poder de influência, não trouxe alterações expressivas para a maioria das consultadas.

Palavras-chave: Representações sociais de gênero. Reestruturação produtiva. Setor de telecomunicações.

\section{INTRODUÇÃO}

Diversos estudos atestam que a inserção da mulher na população economicamente ativa e a sua ascensão educacional nas últimas décadas não vieram acompanhadas de condições igualitárias posto que disparidade salarial, restrição ocupa-

'Graduada em Administração pela Universidade Federal de Santa Catarina - UFSC. Rualosé do Valle Pereira, 200 apto 302, Coqueiros, Florianópolis, SC. CEP: 88080-240. E-mail: patymfigueredo@yahoo.com.br.

2 Mestre em Administração pela Universidade Federal de Santa Catarina - UFSC. Professora do Departamento de Ciências da Administração da Universidade Federal de Santa Catarina - UFSC. Rua Aracuã, 319, Florianópolis SC, CEP 88040-3 I 0. E-mail: lianehz@ hotmail.com . Artigo Recebido em: 18/07/2007. Aceito em: 26/03/2008. Membro do Corpo Editorial Científico responsável pelo processo editorial: Prof. Gilberto de Oliveira Moritz. 
cional e hierárquica são fatores constantes na carreira da maioria das trabalhadoras brasileiras, apesar dessa configuração não ser verificada somente no Brasil, mas em todo o mundo ocidental. Tal conjuntura é decorrência de estereótipos seculares que segrega a mulher a funções nas quais pouco pode exercer sua intelectualidade e que a compele a uma posição de exploração.

Atuando de forma consciente ou não na mente das pessoas, as representações sociais de gênero caracterizam a mulher como um ser dotado de sensibilidade demasiada, de inteligência rasa, submissa e com reduzidas aspirações profissionais já que se entende que sua verdadeira vocação é cuidar do lar.

Essas concepções se revestem de um caráter determinista biológico e ao originar a imagem de toda mulher como uma classe, não como pessoas distintas entre si, nega-lhes sua própria dignidade como ser humano. Nas famílias, as representações sociais de gênero determinam a dupla jornada de trabalho para as mulheres.

Nas organizações, os preconceitos de gênero influenciam suas políticas o que provoca dois efeitos principais: a divisão das atividades de acordo com o sexo e a repulsão de mulheres a cargos de alto comando, ou seja, o denominado fenômeno do teto de vidro. Esses fatores originam a concentração das mulheres nos cargos que têm como quesito habilidades semelhantes às que são demandadas no universo privado e pouca instrução formal, mal remunerados, de baixo reconhecimento social e desvencilhados do poder.

Por outro lado, as organizações atuais vivem sob um paradigma produtivo baseado nos preceitos da designada reestruturação produtiva que as forçam a apresentar um novo modelo de gestão que defende fatores como a qualificação, o envolvimento e a autonomia dos trabalhadores para atingir seus objetivos, diante da conjuntura de globalização e tecnologia na qual estão inseridas.

A adoção de instrumentos importados do modelo japonês como a Gestão da Qualidade Total (GQT ou TQC) exige, em contrapartida, a conquista do comprometimento do trabalhador com a organização em que atua e de uma postura participativa do mesmo. Todavia, verifica-se, de um modo geral, que, no Brasil, a idéia de conceder maior autonomia aos trabalhadores desperta resistência perante $\mathrm{o}$ empresariado nacional.

Diante do exposto, esse artigo - a partir da efetuação de um estudo de caso realizado em uma empresa situada no setor de equipamentos para telecomunicações - busca responder a seguinte pergunta: como as representações sociais de gênero influenciam na vida profissional das mulheres no atual contexto marcado pela reestruturação produtiva?

\section{REPRESENTAÇÕES SOCIAIS DE GÊNERO}

Representações sociais podem ser definidas como estruturas cognitivas referentes a grupos distintos que integram a sociedade, compostas por determinados conceitos 
Percepções de mulheres profissionais em meio ao cenário da reestruturação produtiva...

fundamentais comuns, sendo fruto das relações sociais e que fornecem subsídios para compreender esses grupos e com eles se relacionar, visando satisfazer necessidades rotineiras (MOSCOVICI, 1978).

Representações sociais de gênero, conforme Neves (1994), são símbolos e imagens originados pela cultura que a sociedade determina para cada sexo, as quais atuam como condicionante nas interações sociais. De acordo com o mesmo autor, "é nesse mundo pleno de significados que as relações sociais se estabelecem, e não entre quaisquer indivíduos, mas entre indivíduos sexuados que, por sua vez, construíram esse conjunto de representações" (1994, p.10). Tais representações são utilizadas como uma forma de opressão sobre as trabalhadoras nas empresas.

Certamente, a inserção da mulher atual no domínio público lhe possibilitou pela primeira vez na História governar sua própria vida e orientá-la segundo suas próprias escolhas. No entanto, cabe ressaltar que isso não significa que a diferenciação dos papéis sexuais não coexista ou que tenda a ser eliminada, pelo contrário. De acordo com Lipovetsky (2000, p. 239):

\footnotetext{
A liberdade de se autodirigir se aplica agora aos dois gêneros, mas se constrói sempre em 'situação', a partir de normas e de papéis sociais diferenciados, sobre os quais não há nenhuma indicação de que estejam destinados a um futuro desaparecimento.
}

As organizações utilizam as representações de gênero existentes na sociedade em benefício próprio, impondo condições de exploração a mulheres consideradas aceitáveis devido a esses padrões estabelecidos. Essas representações servem como norteadoras às políticas de Recursos Humanos promovendo a segmentação ocupacional entre os sexos, inclusive nas organizações que sofrem profundas modificações em seus paradigmas produtivos (ABRAMO; TODARO, 1998 apud TEIXEIRA, 2001).

Similarmente às empresas, as famílias passaram, nos últimos anos, por transformações nas relações entre homens e mulheres, mas tal qual as empresas também não romperam com os padrões que sustentam a existência de papéis sexuais. Dessa forma, hoje é comum os homens executarem tarefas domésticas bem como se envolverem, muito mais do que antigamente, na vida dos filhos. Todavia, é importante ressaltar que a atuação dos homens no lar é comparável a de um mero assistente que encara o que faz como um favor que presta à sua mulher, dificilmente ele se vê como responsável pela administração do lar e pela criação dos filhos. Esse papel segue sob predomínio da mulher (LIPOVETSKY, 2000).

Conforme Lipovesky (2000), o modo como os homens e as mulheres relacionam a esfera profissional e a esfera familiar é basicamente distinto. Enquanto os homens as vêem como esferas separadas, as mulheres entendem que elas correspondem a uma unidade. Se para os homens conviver com o universo público e o universo privado 
não significa uma dificuldade, para as mulheres significa enfrentar grandes dilemas e contradições no esforço constante de coligá-los.

Segundo Fonseca (2000), Lobo (1991) e Perreault (1993) à mulher são destinadas atividades profissionais em que habilidades tradicionalmente consideradas femininas são requisitadas. Desse modo, a esfera pública para a mulher, em termos de habilidades e aptidões requeridas, representaria nada mais que uma extensão de sua antiga atuação como dona-de-casa. Além disso, os requisitos de seleção após o período de experiência são diferentes para as mulheres englobando fatores como a aparência e a resignação com que executam as tarefas.

Ao se classificar determinadas tarefas e aptidões como próprias de homens e outras como sendo próprias de mulheres, normalmente, destinam-se às mulheres as que dispensam iniciativa, objetividade, condicionamento físico e intelectualidade. Tendo em vista que essa classificação não se limita a separar os trabalhos de acordo com o sexo, mas estabelece uma hierarquia a que predispõem aos homens os empregos mais rentáveis e de maior status social, é baseada em uma ideologia que subjuga e subestima a capacidade das mulheres (FONSECA, 2000).

Considerando-se que essa configuração geralmente não desperta qualquer questionamento crítico, pode-se inferir que a mesma se origina de uma convicção íntima de caráter determinista biológico de que o fato de ser mulher imputa certas características comportamentais, intelectuais e morais inatas.

Por sua vez, Bourdieu (2003) atenta para a importância dos efeitos que o milenar processo ideológico de transpor as diferenças biológicas em diferenças de papéis sexuais promovido preponderantemente pelas famílias em conjunto com instituições sociais, em especial, o Estado, a Igreja e as escolas ainda exerce na mente das pessoas como desencadeador das posições e das relações desiguais em função do sexo. Conforme o autor, as estruturas sociais fazem com que percebam como uma condição determinada pela fisiologia elementos que são, na realidade, frutos de uma construção histórica pautada nas representações, sendo essa concepção enganosa incorporada até mesmo por estudos científicos.

Desde cedo treinadas pelas famílias e pelas instituições sociais a desenvolverem inclinações e aspirações "femininas", isto é, desassociadas do poder, as mulheres encontram nas organizações cargos disponíveis a elas por serem identificados com características relativas a sujeição e a fragilidades.

A violência simbólica de que as mulheres são vitimas é manifesta não somente pela divisão sexual do trabalho, mas também por detalhes informais do cotidiano a exemplo do hábito masculino de chamar as colegas de trabalho de forma excessivamente pessoal como "querida", "menina" ou de tratar suas objeções como banalidades. Essas atitudes expressam uma forma de evocar sua "feminilidade", em uma tentativa de restringir suas ações. Bourdieu (2003) ressalta que a violência simbólica 
Percepções de mulheres profissionais em meio ao cenário da reestruturação produtiva...

é inconsciente e fruto do trabalho intenso das estruturas sociais que produzem a dicotomia sexual. Assim, muitos homens que não se consideram machistas, muitas vezes, agem de forma preconceituosa em relação às mulheres espontaneamente.

De acordo com Lobo (1991), em seus estudos acerca da classe operária e Perreault (1993) que indica estudos realizados por diversos autores, entre os quais Moliniez e Volkoff, Acker e Van Hauten e Guilbert, a passividade intrínseca das mulheres diante de sua condição desigual é uma falácia. Na realidade, uma análise mais aprofundada sobre o cotidiano das trabalhadoras demonstra que a suposta benevolência feminina é provocada pelo tipo de autoridade que se impõem a elas que é muito mais contundente do que a exercida sob seus colegas homens sendo marcada por aviltações, inclusive de natureza sexual.

Lobo (1991) reforça o pensamento de Bourdieu (2003) ao afirmar que não se pode perder de vista que as organizações refletem a distinção entre papéis de homens e de mulheres existente nas famílias e na sociedade de um modo geral, sob a forma de preconceitos arraigados. A origem das segregações sexuais no trabalho está no ambiente externo das organizações. Porém, não obstante as empresas não produzirem a imagem inferior da mulher, elas a assimila e a consolida.

Nesse contexto, percebe-se o denominado fenômeno do teto de vidro como um tema central para se compreender o complexo paradoxo existente nas organizações atuais nas quais, apesar de numericamente as mulheres praticamente se igualarem aos homens - e também em termos de educação formal - a entrada feminina nos cargos de comando mais visíveis permanece bloqueada (TSUI; EGAN; O'REILLY III, 1992 apud STEIL, 1997).

Tradicionalmente, a problemática concernente à diversidade de grupos sociológicos nas organizações, em especial a questão de gênero, é desprezada pelas teorias de administração. Para Hearn e Parkin (1993 apud STEIL, 1997), a teoria das organizações é caracterizada por considerar as contradições de uma forma superficial ou disfarçá-las, pela distorção dos fatos e por um caráter monolítico. Nas décadas de 70 e 80 , surgiram diversos estudos divergentes aos pressupostos nos quais as teorias organizacionais costumam se basear.

Nessa época, a expressão teto de vidro surgiu para designar um obstáculo tão discreto que assume uma forma transparente, porém sólida a ponto de impedir que a mulher penetre nos níveis de comando das organizações somente por pertencer a esse sexo, independente de sua capacitação profissional (POWELL; BUTTERFIELD, 1994 apud STEIL, 1997).

Convém salientar que as concepções sexuais pré-concebidas impossibilitam avaliar o desempenho das mulheres de maneira neutra e imparcial distorcendo, portanto a análise de suas capacidades. Esse problema pode ser minimizado se a empresa assumir uma postura clara e sistemática em relação à sua política de admissão e de promoção, o que restringiria decisões subjetivas enviesadas pelas representações sociais de gênero. 
Os preconceitos de gênero antes de fomentar a segregação da mulher no sentido vertical o fazem no sentido horizontal. Em verdade, a concentração feminina nos setores funcionais, por impedir que as mulheres adquiram conhecimento prático acerca das áreas que representam o "coração" da empresa e assim, uma experiência mais diversificada, constitui uma das principais razões responsáveis por barrar a ascensão feminina a partir de um certo nível da escala hierárquica (LIPOVETSKY, 2000).

Por outro lado, as análises realizadas por Kanter (1977 apud LIPOVETSKY, 2000) denunciam um determinismo comum imposto em relação à questão de gênero, em especial nas empresas de grande porte atuais. Conforme a estudiosa, a ínfima presença das mulheres no topo máximo de autoridade encontra sua causa no temor suscitado pela idéia de diversidade. Procura-se criar um ambiente seguro e estável nos grupos de alto comando para amenizar o risco de imprevisibilidade das decisões. Dessa forma, a empresa cria mecanismos de repulsão às mulheres bem como a todos os profissionais que - mesmo capacitados - por meio de uma análise superficial e estereotipada destoem do grupo de comando, visando assim a máxima semelhança possível entre esses membros.

Kanter (1977 apud STEIL, 1997) procurou analisar como a representação desproporcional de diversos grupos de identidade influenciou a criação de padrões comportamentais estabelecidos para cada grupo. Powell (1993 apud STEIL, 1997) defende, a partir desse estudo, que o grupo minoritário designado tokens (pequenos e irrelevantes) vê seu desempenho ser menosprezado no exercício de cargos de relevo em função dos preconceitos impostos pelo grupo que forma a maioria. Mulheres chefes estão em posição de token em qualquer organização.

Lipovesky (2000) apresenta idéias semelhantes. Por outro lado, defende que ainda que os estereótipos sobrevivam obstinadamente é inegável que os mesmos estão perdendo sua força. $\mathrm{O}$ autor ressalta que os princípios que orientam as empresas de hoje as compelem ao esforço de estabelecer uma estrutura que atraía e preserve os profissionais mais capacitados e mais talentosos, que seja propícia à criatividade e à adaptação e que propague uma imagem favorável tanto aos trabalhadores como à sociedade.

Contudo, Robbins (1983 apud STEIL, 1997) adverte, acerca desse aspecto, que a estrutura de uma empresa resulta do interesse em satisfazer apenas em um grau mínimo aos objetivos organizacionais priorizando o atendimento às conveniências e às preferências dos membros do topo da hierarquia.

\section{REESTRUTURAÇÃO PRODUTIVA}

O desenvolvimento da globalização econômica em conjunto com a revolução nos campos políticos, sociais e culturais originada pelo surgimento da microeletrônica provocou a obsolescência dos paradigmas produtivos norte-americanos - tayloris- 
mo e fordismo. Os princípios que focalizavam a produção em massa, a divisão do trabalho, a separação entre a criação e a efetuação das atividades, além do estudo de tempos e movimentos, os quais promoveram a geração de riqueza até os anos 70, mostraram-se inadequados frente à instabilidade, principalmente dos mercados e dos fluxos financeiros, na nova conjuntura (TEIXEIRA, 2001).

Reestruturação produtiva pode ser definida como um processo de transformações na estrutura organizacional visando sua flexibilidade e sua integração através da adoção de novas tecnologias, novos modelos organizacionais e de gestão (GIRÃO, 2001).

No Brasil, com a queda das políticas protecionistas, as empresas nacionais ficaram expostas à concorrência externa o que as compeliu ao esforço de se adaptar ao novo modelo de gestão sob pena de serem expulsas do mercado interno (CORRÊA; GIANESI, 1996). Outrossim, os anos 80 foram marcados por importantes acontecimentos na área política - o fim do regime militar - e na área social - a volta fervorosa do movimento operário e sindical - que estimularam a transformação do paradigma produtivo. Paralelamente, a grande crise econômica da década igualmente motivou essa revolução (LEITE, 1994 apud TEIXEIRA, 2001).

O denominado modelo japonês surgiu como uma alternativa mais condizente com as atuais exigências de mercado. Coriat (1994) ressalta a relevância de se entender o modelo japonês como um grupo indissociável de transformações que se refletem não somente em aspectos produtivos e organizacionais, mas também na área de Recursos Humanos requisitando conhecimento e autonomia dos trabalhadores.

Entretanto, a reestruturação produtiva brasileira, de um modo geral, foi revestida de uma natureza conservadora devido ao perfil comportamental dos gestores nacionais que relutaram em fazer com que os trabalhadores se tornassem mais independentes e assumissem maiores responsabilidades, como uma necessidade para atender aos novos princípios de organização de trabalho e às novas tecnologias. Conforme sublinha Coriat (1994, p.12) “os métodos japoneses são, no Brasil, utilizados como ferramentas de racionalização do já existente, sem nada mudar das lógicas fundamentais tayloristas e fordistas que constituem o fundamento da indústria tradicional".

A Gestão da Qualidade Total é uma das ferramentas do modelo japonês que obedece aos requisitos do novo paradigma. Um de seus preceitos fundamentais consiste em fazer com que os trabalhadores assumam por si mesmos o monitoramento de suas funções, bem como, um papel de "cliente interno" diante dos "produtos" entregues por seus precedentes.

As políticas de Recursos Humanos devem caminhar nessa direção e buscarem estimular os funcionários a desenvolverem comprometimento com os objetivos da empresa, como uma condição para o sucesso da TQC. Conforme os principais estudiosos de Qualidade Total, como Campos, Crosby, Juran e Deming, a Administração de Recursos Humanos voltada ao comprometimento deve se guiar pelos seguintes princípios: 
estabilidade, retribuição, desenvolvimento pessoal e profissional, reconhecimento, estímulo à comunicação e pesquisa de ambiente (RUAS; ANTUNES, 1997).

Por outro lado, as práticas e os sistemas mais importantes relacionados ao TQC, de acordo com os mesmos autores, são: plano de cargos e salários, programa de benefícios extra-salariais, planos de formação e de treinamento, sistemas de incentivo, procedimentos regulares de comunicação interna além de sistemas e práticas de acompanhamento do ambiente interno.

Conforme Britto (1997), as empresas que desenvolvem equipamentos para telecomunicações no Brasil estão vivenciando um processo de reestruturação, como resposta à intensificação da concorrência originada pela abertura comercial e pela globalização assim como o avanço da tecnologia, o surgimento de nichos dinâmicos e a modificação estratégica nas posições das organizações do setor.

Fleury (1993) aponta que as organizações inseridas em setores de alta tecnologia se distinguem das componentes de outras esferas no Brasil pela grande atenção despendida para a Administração de Recursos Humanos cujas políticas convergem esforços para desenvolver e manter os denominados profissionais "empreendedores". Para tanto, utilizam formas de remuneração por desempenho, favorecem a comunicação em toda a empresa e estimulam a gestão participativa.

\section{METODOLOGIA}

Esse artigo se baseia em um estudo de caso realizado em uma organização de alta tecnologia. $\mathrm{O}$ estudo de caso consiste em um estudo descritivo direcionado à avaliação de uma unidade. O estudo descritivo, de acordo com Triviños (1987, p.110), "pretende descrever 'com exatidão' os fatos e fenômenos de determinada realidade."

A abordagem utilizada no estudo de caso empreendido é qualitativa. A escolha dessa abordagem foi motivada pela mesma proporcionar uma apreensão mais aprofundada de certa conjuntura. Conforme sublinha Richardson e outros (1999, p. 80), os estudos qualitativos são capazes de "possibilitar, em maior nível de profundidade, o entendimento das particularidades do comportamento dos indivíduos".

A empresa selecionada como objeto de análise nesse estudo atua no setor de equipamentos para telecomunicações na região sul do país. Caracteriza-se como uma organização de médio porte pertencente ao setor privado. A abertura comercial e outras alterações importantes ocorridas a partir dos anos 90 que causaram grandes impactos, especialmente em seu setor, impeliram a empresa a um processo de reestruturação produtiva. A pedido dos dirigentes da empresa foi lhe atribuída uma denominação fictícia: Alfa.

Os sujeitos de pesquisa foram 10 mulheres que trabalham na organização e o Gerente de Recursos Humanos. O perfil das funcionárias escolhidas foi: 
Percepções de mulheres profissionais em meio ao cenário da reestruturação produtiva...

a) a maioria das consultadas ocupa cargos de nível hierárquico intermediário, as demais não exercem cargos de chefia;

b) profissionais que atuam em diferentes setores da empresa;

c) funcionárias contratadas, portanto excluindo estagiárias;

d) a instrução mínima das entrevistadas é o ensino médio ou o curso técnico equivalente.

A partir do objetivo geral foram estabelecidas as seguintes categorias de análise, as quais correspondem aos objetivos específicos da pesquisa: a dupla jornada de trabalho a que as mulheres são submetidas, a divisão de atividades profissionais de acordo com o sexo, o fenômeno do teto de vidro e a reestruturação produtiva.

As técnicas de coleta de dados aplicadas nesse estudo foram compostas por entrevistas semi-estruturadas. As entrevistas empregadas com as profissionais foram realizadas individualmente, em um local privativo da empresa. Inicialmente, em todas elas foi explicado que se tratava de uma pesquisa acadêmica e que as entrevistadas não seriam identificadas. As entrevistas empreendidas com o Gerente de Recursos Humanos e com as profissionais foram todas gravadas em áudio e posteriormente transcritas de modo a preservar totalmente a fidedignidade dos dados coletados. No intuito de resguardar a identificação das consultadas, elas são indicadas por letras do alfabeto.

Certas características da pesquisa impuseram algumas restrições à mesma. Os resultados obtidos por esse trabalho estão delimitados ao campo de estudo por se tratar de um estudo de caso, portanto não podem ser generalizados. Paralelamente, a pesquisa não obedece a critérios estatísticos que permitam estender o resultado a todas as trabalhadoras nem mesmo ao conjunto de trabalhadoras da Alfa.

As escolhas dos sujeitos de pesquisa foram determinadas em conjunto pela pesquisadora e pelo Gerente de Recursos Humanos o que é um fator limitante ao presente estudo, pois a seleção não ocorreu de forma totalmente aleatória. Ressalta-se ainda que algumas informações extraídas dos depoimentos que continham aspectos pertinentes aos objetivos do artigo foram omitidas para garantir o anonimato das trabalhadoras.

\section{A DELICADA RELAÇÃO TRABALHO - FAMÍLIA}

A dicotomia entre os papéis familiares determinados para cada sexo fere o senso de justiça das mulheres que trabalham, assim, é vista com descrédito, como inerente a valores ultrapassados. Nesse sentido, apenas uma das entrevistadas acredita que cabe mais ao homem que a mulher o sustento da casa e somente uma delas acredita que cabe somente à mulher ou principalmente à mulher as atividades do mundo doméstico.

Paradoxalmente, entretanto, todas as entrevistadas casadas demonstraram ser as principais responsáveis pelos trabalhos domésticos. Muito embora várias dentre 
essas não tenham admitido assumirem sozinhas esse papel quando questionadas a respeito disso, seus depoimentos denotam o contrário. Mesmo as solteiras ou as casadas que não têm filhos acreditam que a maternidade influenciaria de alguma forma em suas vidas profissionais.

Vale resgatar Bourdieu (2003) quando se refere à ação das estruturas sociais em originar padrões comportamentais diferenciados em função do sexo. Desse modo, percebe-se a manifestação da influência das estruturas cognitivas impingidas nas atitudes das pessoas. No entanto, os depoimentos colhidos surgem em contraposição ao pensamento do autor porque, ainda que confirmem a relevância da atuação das estruturas sociais refletidas em suas ações, essas pessoas não acreditam na validade dos conceitos que impõem papéis distintos aos sexos, não obstante, procedem tal qual como foram "ensinadas" ou condicionadas. Depoimentos, como os exibidos em seguida, revelam uma submissão da mulher a esses padrões inveterados que inserem o homem no mundo público e a mulher no privado, aos quais mesmo rejeitando ela obedece.

[...] Claro que é... A mulher ainda tem aquele estigma, né? De... Eu sou muito assim centralizadora eu sou muito de... De meter a mão, não gosto de esperar, eu vou e faço [...] então, a mulher é mais assim de ir e fazer. Mas, a responsabilidade é dos dois quando um não pode o outro tem que fazer, quer dizer, tem essa... Se negocia, né? [...] Pra nós mulheres a coisa fica mais pesada, né? Lógico, um filho pequeno te exige mais do que do homem (Entrevistada D).

A mulher é mais treinada pra isso desde criança tá mais acostumada, mas não que cabe à mulher. Eu acho que o homem tem que dividir [...] Mas, eu acho que a mulher por um instinto ela já vai, já faz. O homem tem que ser meio mandado tem que mandar fazer as coisas até mandar a mulher já foi lá, já fez, já tomou a atitude. Então, mais por instinto [...] (Entrevistada B).

Contrariando o pensamento de autores como Lipovestky (2000), os depoimentos dos sujeitos de pesquisa sugerem que nem sempre os planos familiares são os mais importantes. Muitas vezes, os planos de maternidade são os que são postos em segundo plano frente à carreira. Por outro lado, relacionar-se em perfeito equilíbrio com os dois mundos, sem que um cause danos ao outro, parece a elas um desafio inalcançável.

De qualquer forma, há um certo consenso de que os objetivos nas duas esferas não são modificados, mas que são protelados uma em função da outra. Porém, será que o tempo perdido pode realmente ser recuperado sem qualquer prejuízo a conquista de objetivos profissionais? A lucidez de uma das entrevistadas sobre essa questão, conforme se verifica no trecho mostrado abaixo, aponta que, na verdade, a decisão de adiar esperando por um momento ideal em que o nascimento de um filho não acarrete em algum tipo de perda na carreira profissional não passa de uma ilusão se não para todas, ao menos para a maioria das mulheres. 
Percepções de mulheres profissionais em meio ao cenário da reestruturação produtiva...

\begin{abstract}
Não tá na hora de ter um filho, vamos dizer assim. Só que qual é a hora também? Se for pensar assim, qual é a hora? Tu nunca é... Vai programar é... Tu até tenta, mas não tem essa programação, acho que não existe [...] Tem que ter alternativas pra contornar isso. Porque se for programar `Ah, primeiro estudar, até fazer faculdade,' [...] Tu nunca vai... Sempre adiando, adiando [...] eu vou adiando sempre, vai adiando alguns sonhos (Entrevistada $\mathrm{H}$ ).
\end{abstract}

Presumivelmente, os homens também são sacrificados pela distinção de papéis sexuais, ainda que não percebam, pois ao priorizar a vida profissional renunciam em grande medida à vida familiar. Contudo, devido às representações de gênero, eles não convivem com o sentimento de culpa que as mulheres enfrentam nem sofrem dilemas a esse respeito.

\title{
6 PAPÉIS SEXUAIS NO TRABALHO
}

AAlfa apresenta a maioria de seus funcionários do sexo masculino visivelmente, apesar de, segundo algumas entrevistadas, estar havendo uma evolução, ainda que pequena, em relação à quantidade de mulheres na empresa. A organização reproduz nitidamente a divisão sexual do trabalho presente na sociedade, em que os cargos técnicos e de altas chefias são ocupados de forma ínfima pelas mulheres e em áreas como de atendimento e funcionais, a exemplo do financeiro, elas se concentram. Por observação, percebe-se que, exceto nesses setores e na área comercial e de marketing em que, embora os homens sejam maioria, ocorre um maior equilíbrio, a predominância masculina é gritante.

A área de pré-atendimento, ou help desk, em que o Gerente de Recursos Humanos exibe uma preferência declarada para admissão de pessoas do sexo feminino, o trabalho exige baixa qualificação e nenhum conhecimento técnico, pois a atividade se resume a atender inicialmente o telefonema do cliente e passar a ligação para a divisão de atendimento técnico.

É evidente que não se pode desconsiderar que as organizações representam um retrato da sociedade em que estão inseridas e, obviamente, há fatores que fogem à sua alçada de responsabilidade, como a demanda predominantemente masculina por certos cursos e feminina por outros no ensino superior, bem como, nas escolas profissionalizantes. Entretanto, é necessário se considerar o perigo de que esse argumento lógico - especialmente, para uma empresa inserida em um setor tradicionalmente masculino - sirva como um pretexto bastante conveniente para encobrir situações de discriminação.

O Gerente de Recursos Humanos declara que não ocorre qualquer tipo de preconceito ou de restrições a mulheres para o exercício de qualquer função por 
se tratar de uma empresa "leve", que não exige grandes esforços físicos no nível operacional. No entanto, o mesmo se mostra díspar em seu depoimento, pois ora afirma ser indiferente o sexo para exercer qualquer um dos cargos da empresa e que a maior quantidade de homens decorre somente de "uma questão realmente de formação e a pessoa adequada estar na área" e "há uma tendência a que é realmente a gente coloque pelo menos meio a meio dentro da empresa", ora expressa preferência por mulheres para certas funções e a crença de que há setores em que elas obtêm resultados melhores comparados aos homens e vice-versa.

Uma área de atendimento muito melhor uma mulher do que um homem. Ela é muito mais sensível, consegue perceber muito mais rápido as necessidades dos nossos clientes. Porém, quando nós conversamos um pouquinho mais na área técnica, a gente percebe que existe um pouco mais de dificuldade em relação ao homem (Gerente de Recursos Humanos).

Além do setor de atendimento, ele cita "área de relacionamento humano" e marketing como áreas em que as mulheres são preferíveis aos homens. $\mathrm{Na}$ área de desenvolvimento de software, também ele expressa preferência por pessoas do sexo feminino, contudo não para a atividade de desenvolver software, mas para a execução de uma tarefa secundária: "Também na área de desenvolvimento de software, quando a gente fala em interface de software, é importante também o visual e a mulher é bastante visual e isso tem favorecido bastante". Ressalta-se que interface, segundo Ferreira (1993, p.312), significa, "conexão, ligação entre hardwares ou softwares".

Essas perspectivas diferenciais em relação ao sexo que, conscientemente ou não, relega as mulheres aos cargos menos remunerados, de menor exigência de qualificação e de menor prestígio social não somente está em consonância com as representações sociais de gênero, como delas se utilizam para justificá-las e revigorá-las. Quanto mais as mulheres acreditam na validade dessas representações, menos as situações delas decorrentes são contestadas, conforme se pode depreender em trechos dos depoimentos colhidos. Tal situação confirma os resultados de trabalhos obtidos por autores como Fonseca (2000) já indicado.

É a gente tem bastante mulheres na parte de atendimento, né? Telefone. Eu acho que, nessas áreas, a voz feminina é... É faz com que numa situação de crise, onde o cliente liga pra cá de repente um pouco alterado, ele já dá uma freada: 'opa, quem atendeu foi uma mulher’ né? Ele já... Ela é mais amena ela...Ela...Ela não...Não cria conflito. É mais paciente. A parte de emoção dela é melhor nessas área de atendimento, sabe? Então na parte de call center tem muito... Tem muita mulher parte de atendimento. [...] A parte de produção é basicamente homem. É porque é mais braçal, mais operacional, né? Eu acho que tem que ser mesmo um homem lá... (Entrevistada E). 
As representações de gênero, reforçando as colocações de estudiosos do assunto como Bourdieu (2003) e Lobo (1991), não são restritas às políticas formais de uma empresa estão presentes também no cotidiano por meio de cenas aparentemente banais que se analisadas atentamente vislumbram os preconceitos que as mulheres ainda sofrem em seu ambiente de trabalho. Tais situações são graves não somente pelas humilhações que elas ocasionam, mas ainda porque revelam concepções distorcidas ou, no mínimo, sem qualquer comprovação científica a respeito das mulheres e que podem prejudicá-las em qualquer decisão que envolva subjetividade como avaliações, promoções e seleções.

[...] a gente acaba fazendo algumas coisas a la secretária, né? E a gente percebe que é por ser mulher. Como, 'Ah, tem alguma coisa suja. Ah, podem chamar alguém da limpeza?', né? Então, porque não vai e chama? Parou pra pedir pra mim pode passar a mão no telefone e ligar pra limpeza, [...] 'Ah, leva um documento lá [...] tu percebe no detalhe que é pelo fato de ser mulher, isso tu percebe claramente (Entrevista B).

É... A gente tem que provar duas vezes que a gente é capaz. É ... Situações do dia a dia mesmo de[...] A gente... Ser responsável por (tarefa específica $\mathrm{x}$ ) vem uma pessoa de uma outra área e falar e verificar se realmente (o resultado da tarefa) faz sentido, perguntar pra outras pessoas que entendem de (solicitado pela tarefa) se é aquilo mesmo...De dá dúvida, sabe? [...] Tu passa por aquele processo assim: 'será que é isso mesmo? Será que ela é capaz? Será que tá certo?'Aquela coisa...(Entrevistada E).

As entrevistadas não acreditam que os critérios de seleção sejam diferentes para homens e mulheres, pelo menos nos setores em que atuam, apesar de algumas não descartarem essa possibilidade em virtude de o processo de seleção incluir entrevistas com o Gerente de Recursos Humanos, assim como, com o responsável pelo setor e considerarem que, nesses estágios iniciais, a escolha possa ser influenciada por suas tendências e por suas preferências pessoais. De fato, uma delas, que supervisiona um setor, evidenciou seguir critérios ligados à estética, à idade e ao sexo para certo cargo. Outra entrevistada afirmou que, na Alfa, as decisões voltadas à administração de Recursos Humanos não são coesas, ou seja, são diferenciadas de acordo com o perfil dos responsáveis pelas áreas. Como já exposto, o próprio Gerente de Recursos Humanos atribui capacidades diferentes às pessoas em função do sexo.

Por outro lado, a empresa apresenta como um forte fator cultural a presença de estagiários e a efetivação dos que evidenciam melhor desempenho. Por conseguinte, a maioria dos colaboradores foi introduzida na empresa dessa forma. Assim, eles tiveram a oportunidade, em princípio, de mostrar seu potencial. Todavia, a triagem de estudantes interessados nas vagas de estágio ocorre por indicação dos funcionários. Portanto, preceitos subjetivos possuem um poder de influência bastante significativo nas admissões. 
Evidentemente, seguindo a linha de pensamento de Powell e Butterfield (1994 apud STEIL, 1997), se as políticas de seleção não forem bem estruturadas de modo sistemático focadas em avaliar os conhecimentos e as habilidades requeridas ao exercício de determinado cargo para cada candidato de forma imparcial, então estão abertas a arbitrariedades.

\section{TETO DE VIDRO OU AS BARREIRAS IMPOSTAS AOS SONHOS}

Apenas uma das entrevistadas declarou que não possui vontade de ascender profissionalmente. Outra entrevistada manifestou que crescer profissionalmente está ligado a se aprimorar na realização de suas atividades, não necessariamente assumir um cargo de chefia e que o importante é ser "reconhecido". Paralelamente, ambas as entrevistadas responderam que já se envolveram indiretamente em planos ambiciosos e projetos-chave nessa empresa, embora as tarefas que assumam não permitam tal participação. É possível que o reconhecimento esteja sendo usado para reconfortar uma situação de descontentamento.

Afinal, é da natureza humana a necessidade de desafios e, a menos que desempenhem um cargo que permita a exposição a novos estímulos, após um certo período desempenhando a mesma função as pessoas fatalmente se sentem insatisfeitas, ainda que esse sentimento possa ser camuflado por um certo comodismo ou receio de não encontrar alternativas melhores. Logicamente, as pessoas não precisam obrigatoriamente de um cargo de chefia para se realizarem e nem todas apresentam o perfil adequado para assumir essas atividades, mas a movimentação horizontal, muitas vezes, é imprescindível e ocorre muito dificilmente nessa empresa, em quase todos os setores aos quais pertencem as mulheres consultadas.

A política estacionária da empresa é agravada pela parcialidade, apesar de informal, na concessão de promoções. Uma das entrevistadas chega a afirmar que "aqui na empresa é muito machista então, eles acham que a mulher não deve exercer cargo de chefia tem muito disso aqui". Somente duas das entrevistadas declararam que a concessão de promoções não é diferente de acordo com o sexo. Contudo, uma delas pondera que a mulher precisa demonstrar uma performance muito superior do que se fosse um homem para ver sua competência reconhecida e assim poder ascender, e a outra menciona que há uma quantidade menor de mulheres nos cargos de chefia.

Uma das trabalhadoras não soube responder se ocorre ou não diferenças em função do sexo do profissional na política de promoções, todavia acha que a mesma não é clara e que informações que forneçam subsídios para responder a essa questão não são acessíveis. A falta de transparência é um indício de que a política é vulnerável a distorções dessa ordem.

$\mathrm{Na}$ Alfa, a decisão sobre promoção de cargos é tomada a partir da avaliação pessoal da chefia imediata, o que também pode gerar suscetibilidade a decisões 
Percepções de mulheres profissionais em meio ao cenário da reestruturação produtiva...

contrárias à equidade. Conforme o Gerente de Recursos Humanos, o setor, nesse momento, começa a exercer influência nesse processo indicando as pessoas que evidenciem serem mais adequadas.

Percebe-se o vigor dos estereótipos sexuais, quando se indaga o que elas pensam sobre mulheres exercendo cargos de chefia. A maioria das consultadas se mostra favorável baseada nos antigos preconceitos que colocam a mulher como humanitária, sensível, democrática e subjetiva. Interessante observar que nenhuma das entrevistadas manifestou indiferença entre ser chefiada por um homem ou por uma mulher de tal sorte que o sexo, na opinião de alguma delas, não interferisse no estilo de gestão.

A tônica dos depoimentos vislumbra a crença de que a mulher apresenta sua emotividade muito mais desenvolvida do que o homem e que os critérios subjetivos são para ela fatores incisivos que guiam suas ações. É a partir dessa crença, pautada nos estereótipos sexuais, que as entrevistadas defendem ou criticam o exercício feminino em cargos de chefia.

Esse ponto da entrevista evidencia a convicção absoluta de que a mulher é o ser emocional, logo, orientado por suas emoções e o homem o ser racional, assim, guiado pela razão. Cabe resgatar Bourdieu (2003) e Fonseca (2000), quando se referem ao caráter determinista biológico do qual se revestem os preconceitos de gênero, os quais levam as mulheres a serem encaradas como um conjunto de seres iguais, como uma classe rotulada não como seres humanos e dessa forma, pessoas distintas entre si.

Seria a gestão masculina livre da influência da subjetividade? A experiência prática confirma esse estereótipo? A grande importância conferida às políticas informais das organizações que representam fonte de interesse acadêmico há muito tempo comprova que não.

Os depoimentos acerca desse questionamento deixam transparecer também, ao ressaltarem os benefícios da administração conduzida por uma mulher, a postura excessivamente hostil e arrogante que a chefia masculina tende a apresentar no relacionamento com as mulheres, às vezes, até de forma explícita. Uma das entrevistadas exemplifica esse fato relatando que é comum ocorrerem reuniões em que todos os homens supervisores são convocados enquanto as mulheres de mesmo nível hierárquico não o são. Esse pensamento corrobora as conclusões obtidas por Lobo (1991) em suas análises que avaliavam o nível operacional das empresas. Tal fato é camuflado pelas representações sociais de gênero que atribuem à mulher uma sensibilidade exaltada e ao homem atitudes impetuosas.

[...] os homens, eles são muito... Acredito que o stresss é mais elevado. Eu acho que a mulher é assim, ela é mais paciente, mais compreensiva, não que ela não vá cobrar, só que ela cobra de uma forma assim é mais equilibrada, às vezes, os homens, eles tornam-se mais agressivos [...] os homens 


\begin{abstract}
são assim mais ríspidos e as mulheres tem umas que são mais sensíveis, aí elas cai no choro, [...] talvez, não saibam conviver com a mulher que tem um lado muito mais sensível que o homem (Entrevistada I).

[...] às vezes, os homens impõem as coisas e tem que ser daquela forma, as mulheres não, além de saber ouvir mais e são mais abertas... A ouvir idéias e tal acho isso é um ponto positivo, né? Nas mulheres assim, poder ver qual é o real problema, ouvir das pessoas quais são os problemas, quais são as necessidades, [...] (Entrevistada G).
\end{abstract}

Outra característica atribuída à gestão feminina bastante presente nos depoimentos é a perspicácia da mulher tida como mais aguçada dotada de maior capacidade de observação e "mais detalhista". Referente a esse aspecto, Bourdieu (2003) entende que a denominada "intuição feminina" existe, no entanto, não é um poder mágico nascido com as mulheres e sim um atributo gerado a partir de "uma peculiar lucidez de dominado". Conforme o autor, como as mulheres estão sempre sob condições adversas, elas acabam desenvolvendo essa habilidade em função da necessidade que elas apresentam de entender e assim, prever os atos do outro que o homem, por estar em uma posição favorável, não possui.

De acordo com autores já apontados, as mulheres por estarem em uma situação de minoria, especialmente quando em cargos de relevo, situam-se em uma posição permanentemente de grande exposição, em que elas não são consideradas individualmente, mas como uma classe. Resgatando as idéias decorrentes do conceito de token, conforme Powell (1993 apud STEIL, 1997), o desempenho das mulheres quando em cargos de chefia é menosprezado pela avaliação do grupo majoritário das organizações, a qual é enviesada por preconceitos que intensificam as diferenciações entre os grupos. Pressupõe-se que na Alfa, por ser uma empresa onde proporcionalmente os homens prevalecem, esse fator se sobressaia.

[...] as mulheres aqui têm muito mais receio de tomar atitude sabendo que vai ter um bando de homem e que elas tão sendo controladas o tempo inteiro, tão sendo analisadas como mulher não só como profissional [...] o homem feito, vamos supor se for algo negativo, acho que um homem diria assim: ' Ah, foi um erro de trabalho 'não e ela não só como um erro de trabalho, mas 'Ah, é coisa de mulher'. [...].Por mais que a gente trabalhe mais é... O nosso trabalho é visto de menos. A gente sempre tá mostrando mais é... Pelo fato de ser mulher, é bem claro! (Entrevistada B).

Como os estereótipos que criam a imagem da mulher como uma pessoa de pouca inteligência são perceptíveis, elas sabem que precisam obter sempre um desempenho excelente para vencer esse obstáculo, posto que uma única falha já pode ser suficiente para reiterar o estigma que impõem a incapacidade profissional feminina. Desse modo, elas exercem suas atividades permanentemente em meio à tensão e é, 
Percepções de mulheres profissionais em meio ao cenário da reestruturação produtiva...

justamente, esse fator que pode retrair o alcance de resultados de acordo com suas reais aptidões (THIRY - CHERQUES; PIMENTA, 2004). Tal fato é perceptível diante dos depoimentos obtidos.

[...] Eu acho que o que é difícil pra mulher é conseguir provar a sua competência. Sabe aquela história de que a mulher tem que trabalhar em dobro pra... Pra ser... Pra ter a sua competência é... Vista? Eu acho que isso é verdade, sabe? Acho que você tem que trabalhar muito e você não pode errar! [...] Você não pode errar muito! Você não deve errar, né? Pelo menos, você deve se cercar de um máximo de... De... De requisitos pra não errar. Você tem que ter toda a cautela pra não errar! (Entrevistada A).

Dessa forma, pode-se inferir, o que reforça o pensamento de Lipovesky (2000), que as mulheres, de um modo geral, apresentam um comportamento profissional que pende mais para a cautela do que para a ousadia. Com efeito, elas temem se arriscar, elas pensam que as conseqüências de um erro serão extremamente severas e, lamentavelmente, elas têm razão. De fato, conforme Powell (1993 apud STEIL, 1997), há vários estudos que comprovam que os efeitos prejudicais à carreira advindos de falhas cometidas por pessoas na condição de token, como as mulheres em cargos de comando, são muito mais severos que para as demais.

\section{OS CAMINHOS TRAÇADOS PELA REESTRUTURAÇÃO: RUMO À VALORIZAÇÃO DOS TRABALHADORES?}

A reestruturação da gestão de pessoas na Alfa trouxe importantes modificações compatibilizando a área, ainda que de forma incipiente, com os imperativos do paradigma organizacional atual, especialmente com a Gestão da Qualidade Total adotada pela empresa. Dessa forma, foram implantadas algumas políticas de gestão participativa e estratégias de comprometimento.

A visão das funcionárias sobre as mudanças ocorridas na empresa é favorável, de um modo geral, foram apontadas melhorias significativas como o estímulo à participação dos funcionários com sugestões, "um sentimento de equipe maior" e uma integração mais efetiva entre as áreas.

No que concerne à questão de gênero, algumas entrevistadas percebem uma evolução, principalmente, pelo fato de pela primeira vez na Alfa uma mulher ter assumido um cargo de gerência. Esse fato ocorreu a partir das últimas alterações que substituíram vários indivíduos em cargos de chefia por pessoas de fora da empresa ou com menos tempo de organização - inclusive, o próprio Gerente de Recursos Humanos entrou nesse período, quando se decidiu empreender a reformulação da respectiva área. Tal situação demonstra que, desde a sua implementação, a reestruturação produtiva na Alfa origina um relacionamento sem mutualidade da empresa com 
os trabalhadores, pois ao mesmo tempo em que passa a exigir o comprometimento dos mesmos, os descarta prontamente se essa for a alternativa mais prática.

Também se notou progressos sobre a situação da mulher na Alfa pela quantidade de mulheres estar aumentando na empresa, em especial em cargos técnicos, ainda que de forma reduzida e pela observação que algumas estão ascendendo. Outras entrevistadas, no entanto, entendem as mudanças como superficiais no que tange a poder de decisão ou de influência das mulheres na organização mesmo em relação às que exercem cargos de chefia.

Quanto à autonomia ou à maior liberdade para tomar decisões, avaliando os depoimentos, esse fator pode ser constatado na área de engenharia. Infere-se que nos outros setores não houve uma mudança expressiva referente a essa questão. As entrevistadas que não são engenheiras têm liberdade para tomar decisões rotineiras de pequena monta.

Uma característica positiva da cultura da organização apontada, considerando as exigências impostas pelo cenário atual, é a abertura concedida aos funcionários para se comunicar com os superiores. Entretanto, pela análise a certos trechos, depreende-se que reivindicações importantes vinculadas ao progresso das condições de trabalho em seus mais diversos aspectos quando, em uma visão superficial, não pareçam rentáveis são ignoradas ou somente são consideradas e respondidas se as questões não ultrapassam a alçada da chefia imediata. Todavia, a participação dos funcionários referente a sugestões de melhoria e de inovação que estejam diretamente relacionadas ao processo produtivo e que, aparentemente, tragam um lucro imediato, é estimulada.

O ritmo de trabalho na Alfa é "intenso", "acelerado", "frenético", porém preponderantemente, não há um descontentamento quanto a isso, apesar de a rotina ser exaustiva em alguns casos. Em um deles, devido ao volume e a diversidade de informações com que é preciso se trabalhar constantemente pela equipe ser pequena diante da quantidade de projetos a serem realizados. Em outro, o problema poderia ser evitado pela adoção de medidas simples pela administração, conforme se pode observar no depoimento exibido a seguir, que, certamente, trariam menos gastos do que causa o desgaste excessivo do trabalhador, especialmente em longo prazo.

Tal fato, inclusive, é contraditório a uma empresa que lança estratégias de comprometimento aos funcionários. Se há um interesse em estabilizá-los, como não se preocupar com sua saúde? Infere-se que não existe um propósito efetivo em manter os funcionários por grandes períodos acerca de áreas que não sejam de engenharia.

[...] a gente passa o dia inteiro as 08 horas sentados ali, né? A gente levanta pra ir no banheiro e, de repente, pra pegar um café que a gente traz pro lugar, pra nossa mesa e toma sentado na mesa trabalhando, entendeu? Tem casos claro, né? Que, de repente, tem um pouquinho mais 
Percepções de mulheres profissionais em meio ao cenário da reestruturação produtiva...

\begin{abstract}
de tempo, que é raro né? Então, a gente fica lá uns 05 minutos no café. Pra tomar um café![...] Tem pessoas ali que se preocupam muito mais com a postura, com com é... A posição dos braços, das mãos. [...] Mas, não que seja uma preocupação, não vejo isso como uma preocupação da empresa [...] (Entrevistada G).

Então, quando você sai do trabalho é... Você sai exaurida [...] pra mim tá sendo muito é... É... É intenso o ritmo de trabalho, com certeza, tá? Eu não sei quanto tempo a gente suporta nesse ritmo frenético, mas eu também tenho consciência de que isso atende o meu perfil assim eu... Eu quando fico em casa, quando fico sem o que fazer, eu fico muito ansiosa, eu fico... Então, eu tô... Não sei se isso vai fazer mal um dia, mas, por enquanto, tá bom (Entrevistada A).
\end{abstract}

Pode-se constatar a interferência que o trabalho pode assumir na vida pessoal do trabalhador, pois "acostumado" com o ritmo veloz de trabalho ele se sente inquieto nos momentos de folga, em decorrência do próprio trabalho e não, ou pelo menos não somente, da personalidade do indivíduo.

Chama a atenção a história de uma das entrevistadas que trabalha há, praticamente, 20 anos na Alfa. Nas fases iniciais de sua trajetória, ela se "comprometeu" com a organização, inclusive, prejudicando sua saúde. Atualmente, ela é graduanda de um curso aproveitável pela empresa e constata que permanecerá estagnada após a formatura dentro da organização, assim como declararam outras entrevistadas que decidiram continuar seus estudos em nível de graduação ou pós-graduação almejando ascender profissionalmente em cursos que são compatíveis com as atividades da empresa. É interessante observar, novamente, que o comprometimento exigido dos funcionários não é recíproco.

[...] é comum, assim há uns anos atrás, nós estendíamos a nossa jornada até 04 horas além do horário, trabalhávamos aos sábados pra cumprir vendas que a gente fazia, que eram de valores significativos [...] quando terminava essas entregas, eu tava assim bem acabada, estressada e quase doente [...] tu passa, praticamente, 24 horas numa empresa pra poder dar conta do que foi vendido então, não é legal assim porque tu vai pra casa, tu dorme, mas não é um sono reparador. No dia seguinte, tu volta cansada [...] (Entrevistada I).

O controle exercido sob as tarefas realizadas é rigoroso em função da grande demanda de trabalho gerada pela velocidade de crescimento da empresa, pela complexidade e pela mutabilidade da tecnologia. Mencionou-se, a propósito, que até as horas perdidas em saídas para ir ao médico justificadas com atestado precisam ser repostas. As entrevistadas não acreditam que ocorra uma postura diferente da empresa de acordo com o sexo relativo a controle. 
A opinião sobre a avaliação de desempenho $360^{\circ}$, implementada acerca de um ano na Alfa, é discrepante. A idéia em si da avaliação proposta no sentido de proporcionar que os colegas de trabalho, ou seja, "clientes" e pares e não apenas o superior avalie é vista com bons olhos. No entanto, na prática, nota-se problemas relevantes gerados pela negligência e até pela possível falta de preocupação da administração da empresa com seu desempenho que a implantou como um procedimento meramente burocrático, sem estabelecer as adequações devidas, pois em nenhum momento houve interesse de ouvir os funcionários que apontam diversas deficiências importantes do sistema. De acordo com várias entrevistadas, não foi percebida uma mudança substancial, "as pessoas acham que ficou igual" e que constitui apenas "uma forma de tá dentro da ISO, um procedimento da ISO".

Quanto à diferenciação da avaliação para homens e mulheres, predominou a posição de que depende da postura assumida pelos superiores, já que a avaliação $360^{\circ}$ na empresa assume um caráter unilateral como nas avaliações tradicionais, mas elas não percebem essa distinção, de um modo geral. Um ponto interessante levantado é que esse tipo de avaliação, pela sua sistematicidade, pode ser favorável para as mulheres por abordar questões especificas sobre o desempenho profissional contribuindo para sua neutralidade.

No entanto, não foi capaz de mudar a situação das mulheres na Alfa, posto que a "recompensa" para quem alcançou as maiores notas se resume a maior ou a menor remuneração obtida pelo Programa de Participação nos Resultados instituído pela empresa. Acrescenta-se que o PPR é uma questão polêmica entre os especialistas de QVT, no que tange à questão do comprometimento dos funcionários (RUAS; ANTUNES, 1997). Além disso, mencionou-se que, no nível operacional, o Plano de Cargos e Salários atrelado à avaliação de desempenho não é cumprido como determinado.

As entrevistadas inseridas em setores técnicos têm acesso somente a treinamentos específicos, os quais são abundantes, porém as demais não dispõem de cursos de capacitação pessoal. Não há praticamente oferecimento de cursos internos voltados a desenvolvimento nem estímulos para a participação de cursos externos destinados a esse propósito. A comunicação interna que pode identificar o interesse da empresa em envolver seus funcionários obteve melhorias, mas ainda apresenta deficiências que comprometem sua integração.

\section{CONCLUSÕES}

A presença feminina no mercado de trabalho é caracterizada pela sua convergência em determinados setores e ocupações, por distorções salariais e pela 
refração a cargos de comando em virtude da atuação das representações sociais de gênero. Por outro lado, a globalização, a abertura comercial e os avanços tecnológicos compelem as organizações atuais a assumirem um novo sistema de gestão e de organização do trabalho, de acordo com os desígnios da denominada reestruturação produtiva que propõe uma revolução na relação das empresas com os seus funcionários ao promover fatores como a autonomia, o comprometimento e a qualificação dos trabalhadores.

Diante dessa conjuntura, esse artigo pretendeu responder a seguinte questão: como as representações sociais de gênero influenciam na vida profissional das mulheres no atual contexto marcado pela reestruturação produtiva? $\mathrm{O}$ universo de pesquisa foi uma organização inserida no setor de equipamentos para telecomunicações. Os sujeitos de pesquisa correspondem a 10 de suas trabalhadoras e a seu Gerente de Recursos Humanos.

No que concerne ao relacionamento entre a vida familiar e a profissional, percebe-se que - muito embora elas não acreditem na divisão tradicional que atribui ao homem a responsabilidade principal pelo sustento da família e à mulher a responsabilidade única ou predominante pelos trabalhos domésticos e pelo cuidado com os filhos - a dupla jornada de trabalho constitui uma realidade para as mulheres devido à atuação das representações sociais de gênero que impõe padrões comportamentais distintos para homens e mulheres.

A divisão de atividades profissionais de acordo com o sexo do trabalhador ocorre na empresa. Tal situação não decorre somente de fatores sociais como a formação educacional diferenciada para homens e mulheres, mas também de alguns aspectos da cultura organizacional da Alfa.

Em referência ao fenômeno do teto de vidro, verifica-se que o mesmo incide sob a organização atuando como um inibidor à ascensão profissional das mulheres. Entretanto, esse fator é um agravante de uma política de imobilidade da empresa, tanto no sentido vertical quanto no horizontal, existente em praticamente todos os setores nos quais estão inseridas as mulheres entrevistadas.

No que tange a poder de influência dos trabalhadores, conclui-se que as mudanças se restringiram ao setor de engenharia ou de acordo com nível hierárquico relativo ao cargo. A maioria das mulheres ouvida nessa pesquisa está autorizada a tomar somente decisões rotineiras e de pouco alcance, elas não ampliaram sua autonomia com essas modificações. Além disso, constata-se que, considerando as exigências do atual contexto, a Alfa privilegia medidas que originem lucro imediato, contudo pouco empreende em relação a estratégias que promovam comprometimento efetivo do trabalhador, especialmente, o que não integra áreas de engenharia. 
Patrícia Maria Figueredo • Liane Carly Hermes Zanella

\title{
PERCEPTIONS OF PROFESSIONAL WOMEN IN THE PRODUCTIVE RESTRUCTURING SCENARIO: PERSISTENCE OF A LIMITED EMANCIPATION?
}

\begin{abstract}
This research aims to evaluate how social gender representations have influenced the professional lives of women within the current context denoted by productive restructuring. With that in mind, a descriptive study was carried out in an organization of the telecommunication equipment sector. The data gathering technique adopted included semi structural interviews. The interviewees had to work double shifts. Gender based professional activities division could be verified in this organization and was, in part, a consequence of aspects that are inherent to its organizational culture. A phenomenon known as "glass ceiling"; a subtle barrier which hinders women's professional growth ; could also be observed. As for autonomy and influence power, the advent of productive restructuring has brought no significant modifications to most of the women who were interviewd.
\end{abstract}

Keywords: Gender social representations. Productive restructuring. Telecommunication sector.

\section{REFERÊNCIAS}

BOURDIEU, Pierre. A dominação masculina. 3. ed. Rio de Janeiro: Bertrand Brasil, 2003.

BRITTO, Jorge. Reestruturação industrial e impactos sobre o emprego: a experiência do setor de equipamentos para telecomunicações. In: CARLEIAL, Liana; VALLE, Rogério (Org.). Reestruturação produtiva e mercado de trabalho no Brasil. São Paulo: Hucitec - ABET, 1997.

CORIAT, Benjamin. Pensar pelo avesso: o modelo japonês de trabalho e organização. Rio de Janeiro: Revan: UFRJ, 1994.

CORREAA, Henrique; GIANESI, Irineu. Just in time, MRP II e OPT: um enfoque estratégico. São Paulo: Atlas, 1996.

FERREIRA, Aurélio Buarque de Holanda. Minidicionário da língua portuguesa. 3. ed. Rio de Janeiro: Nova Fronteira, 1993. 
Percepções de mulheres profissionais em meio ao cenário da reestruturação produtiva...

FLEURY, Maria Tereza Leme. Mudanças e persistências nos modelos de gestão de pessoal em setores de tecnologia de ponta: o caso brasileiro em contraponto ao japonês. In: HIRATA, Helena (Org.). Sobre o modelo japonês: automatização, novas formas de organização e de relações de trabalho. São Paulo: Editora da Universidade de São Paulo, 1993.

FONSECA, Tânia Mara Galli. Gênero, subjetividade e trabalho. Rio de Janeiro: Vozes, 2000.

GIRÃO, Isabel Cristina Carpi. Representações sociais de gênero: suporte para as novas formas de organização do trabalho. In: PIMENTA, Solange Maria; CORRÊA, Maria Laetitia (Org.).Gestão, trabalho e cidadania: novas articulações. Belo Horizonte: A.autêntica/ CEPEAD/ FACE/ UFMG, 2001.

LIPOVETSKY, Gilles. A terceira mulher: permanência e revolução do feminino. São Paulo: Companhia das Letras, 2000.

LOBO, Elisabeth Souza. A classe operária tem dois sexos: trabalho, dominação e resistência. 1. ed. São Paulo: Editora Brasiliense, 1991.

MOSCOVICI, Serge. A representação social da psicanálise. Rio de Janeiro: ZAHAR Editores, 1978.

NEVES, Magda de Almeida. Trabalho e cidadania: as trabalhadoras de Contagem. Petrópolis: Vozes, 1994.

PERREAULT, Michel. A diferenciação sexual no trabalho: condições de trabalho diferentes ou uma questão de sexo? In: CHANLAT, Jean - François. O indivíduo na organização: dimensões esquecidas. v. 2. São Paulo: Atlas, 1993.

RICHARDSON, Roberto Jarry et al. Pesquisa social: métodos e técnicas. São Paulo: Atlas, 1999.

RUAS, Roberto; ANTUNES, Elaine. Estruturação, programas da qualidade e práticas de benefícios e incentivos: a questão do comprometimento. In: CARLEIAL, Liana; VALLE, Rogério (Org.). Reestruturação produtiva e mercado de trabalho no Brasil. São Paulo: Hucitec - ABET, 1997. 
STEIL, Andréa Valéria. Organizações, gênero e posição hierárquica - compreendendo o fenômeno do teto de vidro. Revista de Administração, São Paulo, v.32, n.3, p.62-69, julho/setembro 1997.

TEIXEIRA, Alessandra Luisa. Trabalho feminino e reestruturação produtiva: formas reconfiguradas de exploração ou novos horizontes de emancipação? In: PIMENTA, Solange Maria; CORRÊA, Maria Laetitia (Org.).Gestão, trabalho e cidadania: novas articulações. Belo Horizonte: A.autêntica/CEPEAD/FACE/UFMG, 2001.

THIRY - CHERQUES, Hermano Roberto; PIMENTA, Roberto da Costa. A vitória aparente: a ética e a mulher nas empresas. ESPM, São Paulo, julho/agosto 2004.

TRIVIÑOS, Augusto Nibaldo Silva. Introdução à pesquisa em ciências sociais: a pesquisa qualitativa em educação. São Paulo: Atlas, 1987. 